\title{
RECOMMENDATIONS ON DEVELOPING LEADERSHIP STYLE FOR THE CONTINGENT OF LEADERS AND MANAGERS OF MILITARY SCHOOLS FOLLOWING HO CHI MINH LEADERSHIP STYLE
}

\section{Thanh Phung}

\section{Article History}

Received: June 17, 2020

Accepted: September 3, 2020

Published: September 30, 2020

\section{Keywords}

Ho Chi Minh, leadership

style, leading and managing

cadres, military school
Political Academy - Ministry of Defence, Vietnam

Email:phungchithanh77@gmail.com

\section{ABSTRACT}

Nowadays, the contingent of leaders and managers in military schools has an especially important position, directly contributing to the successful implementation of the task of educating and training high-quality human resources for the sake of building Vietnam People's Army to become revolutionary, regular, elite, and gradually modernized. Building a proper leadership style for leaders and managers in military schools is the foundational, long-term task and an urgent issue. The article summarizes the history of research and presents the fundamental contents of Ho Chi Minh's leadership style as well as the application in building leadership styles for leaders and managers at military schools.

\section{INTRODUCTION}

Ho Chi Minh's style is an important part of the entire invaluable heritage that he has left to our nation as well as to the mankind. In his style system, leadership style is an important content, reflecting the perception, thoughts, actions and practical results of President Ho Chi Minh. His leadership style has become an example, a valuable lesson, a standard for building the leadership style of the revolutionary cadre in general, of the leadership and management staff at military schools in particular.

The current contingent of leaders and managers at military schools is a large force, prominent of political qualities, ethics, and scientific thinking; acting as the foundational and direct force of the military personnel training and fostering process. In order to fulfill the roles as well as their leading and managing functions on specific assigned positions, the requirements for the staff lie in not only the stability of capacity and professional qualifications, but above all the possession of a democratic, scientific and effective leadership style. Therefore, developing leadership styles for the cadres who are leaders and managers at current military schools in Ho Chi Minh style is a meaningful and urgent mission that directly contributes to the consolidation, development and improvement of the quality and capacity of the cadres of leaders and managers at military schools in order to manifest in practice, thereby becomes a crucial factor that determines the quality and effective implementation of the Politburo's Directive No. 05-CT/TW on continuation to promote learning and practicing Ho Chi Minh's ideology, ethics, and style.

\section{LITERATURE REVIEW}

In consideration of Ho Chi Minh's style in general, Ho Chi Minh's leadership style in particular as well as its application in building leadership styles for the leading and managing cadres at military schools has been provoking the research interest of many domestic and foreign scholars, scientists, and management leaders over the years. In recent years, a number of prominent works have emerged such as Nguyen The Thang (2011), "Ho Chi Minh's ideology on leadership style"; Nguyen Ngoc Anh (2013), "Ho Chi Minh's leadership style"; Nguyen Huu Dong (2014), "Delicate leadership: characteristics in Ho Chi Minh's ideology about the Party's ruling and leadership culture"; Propaganda Department of Central Communist Party (2016a), "The foundational contents of Ho Chi Minh's ideology, ethics and style"; Dinh Ngoc Quy (2017), "Ho Chi Minh's ideology on social leadership"; Nguyen Viet Hien (2018), "Ho Chi Minh's leadership style"; Propaganda Department of the Central Committee (2018), "Building the style and working style of the leaders, cadres and party members in studying and following Ho Chi Minh's ideology, ethics and style"; Tran Minh Truong (2018), "Building working style for heads of committees, agencies and units according to Ho Chi Minh's ideology, ethics and style"; Pham Thi Huyen (2018), "Building leadership styles for key provincial cadres in the northern mountainous region in Ho Chi Minh style"; Ly Viet Quang, Tran Thi Hoi (co-authors, 2019), "Ho Chi Minh style of leadership and management: Values, theory and practice". 
The studies of the above authors have shown the general and relatively clear picture of the methodological approach of Ho Chi Minh's leadership style and its academic value, a principled issue as well as the content and solutions to building the leadership style of the Party cadres and members. These studies provide important significance and considerable scientific arguments to approach and apply to the research topic "Recommendations on developing leadership style for the contingent of leaders and managers of military schools following Ho Chi Minh leadership style".

\section{RESEARCH METHODS AND RESULTS \\ 3.1. Research methods}

The paper uses specialized and interdisciplinary research methods, which focus on procedures such as logical and historical methods, analysis and synthesis, statistics and comparison, and literary research methods and expert methods to explain scientifically the issues posed on Ho Chi Minh's leadership style on developing leading and managing cadres at current military schools.

\subsection{Research results}

\subsubsection{Ho Chi Minh's leadership style}

Leadership style is a combination of unique and stable methods, measures, and ways that a leader uses in the process of influencing the leadership object to achieve the set goals. Leadership style reflects the individual character of a leader through a system of relatively stable and characteristic methods of action when they deal with leadership situations. It is flexible rather than rigid, depending on various leadership situations. Usually, leadership styles exist as a potential, since only when a leader handles a leadership situation will his or her leadership style manifest and apply to that situation. Leadership is not a spontaneous form but a well-defined process. To have an effective leadership style, the leader must be regularly educated, fostered and trained to possess comprehensive knowledge and practical capabilities. They must be really proactive, flexible, and quick to grasp and handle situations in the most effective direction.

Ho Chi Minh's leadership style is highly characteristic, unique and stable, which was regularly shown in his leadership activities. Ho Chi Minh's leadership styles consist of different categories: scientific, dynamic, and creative style; democratic but assertive style; leadership style that deeply adheres to the public; exemplary style with model and commitment. Ho Chi Minh's leadership style has great theoretical and practical value for the revolutionary cause of the Party and the people of Vietnam. It contains and conveys many traditional cultural values of the East, the West, the past, the present, the future and is expressed in the following specific contents:

Firstly, it is the public orientation style. This is the most important content in Ho Chi Minh leadership style, expressed firstly in its immense love and endless trust in the people. As the head of the Party and State, the supreme leader of a country, President Ho Chi Minh shared an extremely close and considerate relationship with the public, understanding and sharing all thoughts and aspirations of the People, deeply grasping the practical situation, especially the life, psychology and culture of the People to give serious consideration about their legitimate and practical interests. He always followed the ideal: "All people shall have enough food, clothes, and education" (Secretariat of the Party Central Committee, 2011e, p. 187), "Of all the ways to organize and work, the ones to follow are for the benefit of the public. Therefore, if the organization and the way of working are yet approachable for the public, we must have the courage to propose to higher levels to dismiss or reform." (Secretariat of the Party Central Committee, 2011f, p. 286). At the same time, he has repeatedly criticized the bureaucracy, bossy, and despised attitude of officials towards the people. He gave strong criticism to the leaders who lacked public-oriented working opinion and style: “... is the officer in charge but sets oneself away from reality, away from the public. Tasks are done with no careful investigation and research. Directions are rough and general. Failure to listen to the public opinion; practice non-democratic behaviors. Fear of criticism and self-criticism. Failure to keep the principles of collective leadership, assignment of responsibility." (Secretariat of the Party Central Committee, 2011b, p. 574).

Secondly, it is the combination of principle with flexibility and creativity. President Ho Chi Minh instructed the revolutionary cadres to "Be loyal to the Party", "Be loyal to the Nation, be filial to the People" because this is the foundational quality throughout all activities of the revolutionary cadres. Therefore, according to President Ho Chi Minh, the key aspect in the leadership style of the leading cadres is to: "Work hard for the Party, maintain the Party's discipline, fully implement the Party's guidance and policies; put the interests of the Party and the People of the labor force firstly, prior to their own personal interests. Wholeheartedly serve the People. For the Party, for the People, we struggle to sacrifice ourselves and be exemplary in everything." (Secretariat of the Party Central Committee, 2011c, 
p. 603). President Ho Chi Minh also stressed that those who do not have any initiatives are not considered leaders. On the other hand, dynamism and creativity can only be successful when it is done on the basis of correct orientations with certain principles. Getting rid of principles in the name of dynamism and creativity will eventually lead to mistakes and failures.

Thirdly, it is the combination of revolutionary enthusiasm with scientific thinking. In his work as well as in leadership, President Ho Chi Minh always required cadres and party members, especially leading cadres to be "virtuous" and "talented" people, in which virtue is the original and indispensable characteristic. Virtue and talents is "rose" and "specialization" respectively. First of all, they need to have revolutionary enthusiasm because only with revolutionary enthusiasm can the revolutionary cadres bear the glorious but increasingly heavy responsibility to the Party and the People in the revolution of liberation and in the current renovation. However, revolutionary enthusiasm is only truly effective when combined with honesty, objectivity, and science. It will become idealistic and theoretical if there is a lack of scientific knowledge, gradually leading to mistakes, misdirection, harmful guidance, policies and actions, even resulting in unconscious destruction. Along with that, President Ho Chi Minh paid special attention to the scientific leadership style that must be guaranteed by scientific knowledge. Accordingly, He requested: "Whatever the circumstances, Party members and cadres need to always strive, work hard, study hard to improve their cultural knowledge and political level". Scientific leadership style requires staff to have a clear, focused purpose and a coordinated plan regardless of what they do. "The target is to be accurately aimed and shot at", He said. "If there are too many, not one could be hit." (Secretariat of the Party Central Committee, 2011f, p. 374). He also strongly criticized the officials whose "work program is too extensive but lacks practicality".

The fourth is the unity between the leadership team and the individual in charge and assertiveness. Ho Chi Minh always respected the People's ownership, wholeheartedly served the People, listened to their opinions, had good relations with them, and learned from them. He affirmed that our regime is "democracy is for the People to take ownership" and when the People take ownership, the leadership must be democratic. He said, "No one can understand everything or do everything. Even the leading hero is the same. Compared to the work of the entire human race in the world, the work of ancient great heroes just only fulfilled their single part." (Secretariat of the Party Central Committee, 2011f, p. 256). Therefore, he asked each officer to learn to gather the talents and intellect of the collective to reach for the common goal. This can only be made possible if a real democratic atmosphere is developed internally.

The fifth is the unification between theory and practice, commitment and implementation. As President Ho Chi Minh reminded, leading cadres needed theoretical reasoning to fulfill their tasks. He emphasized, "Reasoning is like a guideline; it shows our direction in the practical work. Without reasoning, it is as confusing as walking while closing your eyes "(Secretariat of the Party Central Committee, 2011f, p. 273-274), "working without reasoning is no different than walking in the dark, slowly and stumbling everywhere" (Secretariat of the Party Central Committee, 2011g, p. 357). Along with that, He also always posed the necessary requirement to know the relationship of theoretical reasoning with practical working. According to President Ho Chi Minh: "Reality without guiding reasoning becomes a blind practice. Reasoning without relation to practicality is just an empty argument." (Secretariat of the Party Central Committee, 2011a, p. 497). He advised each officer to constantly improve reasoning, associate learning theoretical research with practical work, because "Reasoning like an arrow (or a bullet). Practice is the target. Having an arrow but unable to shoot, or missing the target, then there is no use." (Secretariat of the Party Central Committee, 2011f, p. 275). At the same time, he specially noted that, for the People, who could not understand purely theoretical reasoning, it is necessary to show the practical benefits from good examples and practical work of the cadres. He said: "It must take practical results, on how much of your contribution to production and production leadership, to measure your revolutionary will. Be determined to get rid of the bureaucracy, unfulfilled commitments, and unproductive working methods" (Secretariat of the Party Central Committee, 2011d, p. 68).

3.2.2. The current situation of developing leadership style for the contingent of leaders and managers of military schools following Ho Chi Minh leadership style

Over the past years, the development of leadership styles for leading cadres and managers at military schools has achieved remarkable results. The vast majority of party committees and organizations in military schools have had right awareness, high responsibility, and great consideration about leadership, and have directed to build leadership styles for the contingent of leaders and managers; the content, programs, forms and measures to build leadership styles for leaders and managers at military schools have been constantly reformed and gradually crafted to meet the 
practical requirements... Thanks to that, the leadership style of leaders and managers at military schools is constantly developing, maturing, and always exemplary in morality, lifestyle, and disciplined obedience, truly becoming a center of solidarity and high credit in the party organization and unit, capable of meeting the requirements of assigned functions and tasks.

In addition to the above advantages, the process of developing leadership styles for leaders and managers at military schools still has certain limitations and shortcomings. More specifically, the leadership and direction of leadership for the development of leading and managing cadres at military schools in a number of party committees, party organizations, and leading cadres is not regular and continuous; some training content lacks specificity and has yet been separated from the content of the annual general training and politics fostering program; missing the attention to the form of training and self-training in terms of leadership style for the leaders and managers. At the same time, a number of leaders and managers at military schools still lacks a sense of self-discipline to study, practice, and improve their own quality, capacity, and leadership style. The situation has left severe impacts, becoming a significant obstacle to the process of developing leadership styles for leaders and managers at military schools and called for timely remedial measures.

3.2.3. Recommendations on developing leadership style for the contingent of leaders and managers of military schools following Ho Chi Minh leadership style

Developing the leadership style of leading cadres and managers at military schools according to Ho Chi Minh leadership style is the process of researching, thoroughly grasping and creatively applying the content and characteristics of Ho Chi Minh's leadership style in the process of education, fostering, training, ensuring that the leadership and management staff at military schools have an advanced, correct and scientific leadership style that responds to assigned positions, roles, responsibilities, and duties. In the current situation, in order for the process of building leadership styles for the cadres of leaders and managers at military schools in Ho Chi Minh style to bring about practical results, it is necessary to focus strongly on the following key contents:

Firstly, attach importance to the promotion of the leadership role of the party committees, party organizations, the guidance and administration of political agencies in developing leadership styles for leading and managing cadres at military school. As the subject of leading, directing, managing and administering the process of improving the quality and capacity of the leaders and managers at military schools, first of all, it is required for the party committees, the commanders and political bodies in military schools to have proper awareness, promote responsibility for leadership, closely direct the development of leadership styles for leading cadres and subordinate managers; to manage and properly evaluate the quality, capacity, leadership style of each leading officer; to promptly have guidelines, plans, determination of the content, form and method of developing leadership quality, close and appropriate competence and style. At the same time, it is essential to proactively foster the source of leadership and management cadres in high-quality military schools, connect the strengthening of the party committee with the arrangement of leading cadres, and step by step rejuvenate the contingent of leading cadres in terms of direction and management at all levels.

Secondly, promote the activeness and self-awareness of each leader and manager at military schools in terms of self-studying, training and developing leadership style. The results of developing the leadership style of the cadres of leaders and managers at military schools depend first and foremost on the sense of self-awareness, actively learning, practicing and fostering attitude of each officer. The contingent of leaders and managers at military schools is both the object of the development process, and the subject of the self-learning, training to improve leadership qualities, competencies and style process. Accordingly, the party committees and leading officials at all levels should have guidelines and measures to lead, direct the planning, determine the content and form, as well as create favorable conditions and encouragements in order to build a sense of self-discipline to learn and practice to develop leadership style for the contingent of the subordinate leading cadres and managers; at the same time regularly monitoring, examining and evaluating the results, promptly detecting and rectifying errors and deviations; proactively engage through practical activities to build leadership styles for the team of leaders and managers.

Thirdly, associate the leadership style development for the contingent of leading cadres and managers in military schools with the development of party committees, concrete and pure grassroot party organization, and comprehensively strong units. It can be seen that the leadership capacity and combat strength of the party committee, grassroot party organization as well as the results of the unit's operation are the reflection from the results of leadership and direction, both playing a great impact on the quality and effectiveness of the leadership style 
development process of the leadership team at military schools. As the contingent of leading cadres and managers at military schools is often elected, or appointed as secretary or deputy secretary of the party organization in the unit, the strong purity of the Party's grassroot organization as well as the comprehensive strength of the agencies and units will be a favorable environment for the leaders and managers to constantly strive, cultivate and improve their leadership qualities, competencies and styles.

Fourthly, utilize the preliminary and summary activities to draw experience in developing leadership styles for the contingent of leading and managing cadres at military schools. The process of developing the leadership style for the contingent of leading and managing cadres at military schools is a foundational and long-term process that requires both working and learning from experience. Therefore, the party committees and the leaders of the political organizations of military schools must periodically perform the preliminary work well in order to summarize, assess the pros and cons, clarify the causes and draw out the experiences to improve the quality and efficiency of the process of developing leadership styles for the subordinate leading and managing cadres.

\section{DISCUSSION AND CONCLUSION}

Ho Chi Minh's leadership style was formed on the basis of inheriting the values and personality of the Vietnamese people and ethnicity while absorbing the quintessence of human culture, elevating through the Marxist-Leninist styles viewpoint. It is the combination of tradition and modernity, Eastern and Western culture that created in Ho Chi Minh an exemplary image of a leader, a wise philosopher with "great kindness, great intelligence, great courage"; a leader who wholeheartedly serves the People, believes in the People, connects with all the People of labor, honored with complete respect and admiration. The leadership style is not only valid for the past and present but also has a directional value for the future. The process of applying Ho Chi Minh's leadership style to developing leadership styles for leaders and managers at military schools is an extremely important and urgent matter, ensuring for the contingent of cadres leading and managing military schools to be comprehensively developed, meeting the practical requirements of the country's revolutionary mission in the new situation.

\section{REFERENCES}

Communist Party of Vietnam (2011). Document of the XI National Congress of Delegates. National Political Publishing House.

Communist Party of Vietnam (2016a). Directive No. 05-CT/TW dated May 15, 2016 on Promoting learning and practice Ho Chi Minh's ideology, ethics and style.

Communist Party of Vietnam (2016b). Document of the XII th National Congress of Delegates. National Political Publishing House.

Dinh Ngoc Quy (2017). Ho Chi Minh's ideology on social leadership. Doctoral thesis in Politics, Ho Chi Minh National Academy of Politics.

Ly Viet Quang, Tran Thi Hoi (co-editor, 2019). Ho Chi Minh style of leadership and management: Values, theory and practice. National Political Publishing House.

Nguyen Huu Dong (2014). Delicate leadership: characteristics in Ho Chi Minh's ideology about the Party's ruling and leadership culture. Vietnam Journal of Social Sciences, Vietnam Academy of Social Sciences, 10, 3-12.

Nguyen Ngoc Anh (2013). Ho Chi Minh's leadership style. Vietnam Journal of Social Sciences, Vietnam Academy of Social Sciences, 1, 19-25.

Nguyen The Thang (2011). Ho Chi Minh's ideology on leadership style. Journal of Political Theory, 9, $20-25$.

Nguyen Viet Hien (2018). Ho Chi Minh's leadership style. Propaganda Review, Central Propaganda Department. Accessed at http://tuyengiao.vn/theo-guong-bac/phong-cach-lanh-dao-ho-chi-minh-111332

Pham Ngoc Anh (editor, 2015). Ho Chi Minh's leadership style - Theoretical and practical value. People's Public Security Publishing House.

Pham Thi Huyen (2018). Building leadership styles for key provincial cadres in the northern mountainous region in Ho Chi Minh style. Doctoral thesis of Ho Chi Minh, Ho Chi Minh National Academy of Politics.

Propaganda Department of Central Communist Party (2016a). The foundational contents of Ho Chi Minh's ideology, ethics and style. National Political Publishing House.

Propaganda Department of Central Communist Party (2016b). The foundational contents of Ho Chi Minh's ideology, ethics and style (Research documents serving the implementation of the Politburo's Directive No. 05-CT/TW on Promoting learning and practice Ho Chi Minh's ideology, ethics and style). 
Propaganda Department of the Central Committee (2017). Instruction No. 52-HD/BTGTW dated 20/11/2017 guiding the thematic study in 2018 "Building the style and working style of the leaders, cadres and party members in studying and following Ho Chi Minh's ideology, ethics and style”.

Propaganda Department of the Central Committee (2018). Building the style and working style of the leaders, cadres and party members in studying and following Ho Chi Minh's ideology, ethics and style. National Political Publishing House.

Secretariat of the Party Central Committee (2011a). Ho Chi Minh City (Book 8). National Political Publishing House.

Secretariat of the Party Central Committee (2011b). Ho Chi Minh Complete Collection (Book 10). National Political Publishing House.

Secretariat of the Party Central Committee (2011c). Ho Chi Minh Complete Collection (Book 15). National Political Publishing House.

Secretariat of the Party Central Committee (2011d). Ho Chi Minh Complete Collection (Book 3). National Political Publishing House.

Secretariat of the Party Central Committee (2011e). Ho Chi Minh Complete Collection (Book 4). National Political Publishing House.

Secretariat of the Party Central Committee (2011f). Ho Chi Minh Complete Collection (Book 5). National Political Publishing House.

Secretariat of the Party Central Committee (2011g). Ho Chi Minh Complete Collection (Book 6). National Political Publishing House.

Tran Minh Truong (2018). Building working style for heads of committees, agencies and units according to Ho Chi Minh's ideology, ethics and style. Communist Review. Available at http://www.tapchicongsan.org.vn/hoc-tapva-lam-theo-tu-tuong-ao-uc-phong-cach-ho-chi-minh1/-/2018/52464/xay-dung-phong-cach-cong-tac-cua-nguoidung-dau-cap-uy\%2C-co-quan \%2C-don-vi-theo-tu-tuong\%2C-dao-duc\%2C-phong-cach-ho-chi-minh.aspx 